\title{
Clinical efficacy of 60-mg dexlansoprazole and 40-mg esomeprazole after 24 weeks for the on-demand treatment of gastroesophageal reflux disease grades $A$ and $B$ : a prospective randomized trial
}

\author{
Hung-Hsien Chiang' \\ Deng-Chyang $\mathrm{Wu}^{2}$ \\ Pin-I Hsu ${ }^{3}$ \\ Chao-Hung Kuo ${ }^{2}$ \\ Wei-Chen Tai \\ Shih-Cheng Yang' \\ Keng-Liang Wu' \\ Chih-Chien Yao' \\ Cheng-En Tsai' \\ Chih-Ming Liang' \\ Yao-Kuang Wang ${ }^{2}$ \\ Jiunn-Wei Wang ${ }^{2}$ \\ Chih-Fang Huang ${ }^{4}$ \\ Seng-Kee Chuah' \\ on behalf of the Taiwan Acid- \\ Related Disease Study Group \\ 'Division of Hepato-Gastroenterology, \\ Department of Internal Medicine, Kaohsiung \\ Chang Gung Memorial Hospital and Chang \\ Gung University College of Medicine, \\ Kaohsiung, Taiwan; ${ }^{2}$ Division of \\ Gastroenterology, Department of Internal \\ Medicine, Kaohsiung Medical University \\ Hospital and Kaohsiung Medical University, \\ Kaohsiung, Taiwan; ${ }^{3}$ Division of \\ Gastroenterology, Department of Internal \\ Medicine, Kaohsiung Veterans General \\ Hospital, National Yang-Ming University, \\ Kaohsiung, Taiwan; ${ }^{4}$ Division of Family \\ Physicians, Kaohsiung Chang Gung Memorial \\ Hospital and Chang Gung University \\ College of Medicine, Kaohsiung, Taiwan
}

Correspondence: Chih-Ming Liang Division of Hepatogastroenterology, Department of Internal Medicine, Kaohsiung Chang Gung Memorial Hospital and Chang Gung University College of Medicine, 123 Ta Pei Road,

Niao-Sung District, Kaohsiung 833,

Taiwan

Tel +88 $6773 \mid 7 \quad$ I23 2360

Fax +8 8677322402

Email gimy5486|439@gmail.com
This article was published in the following Dove Press journal:

Drug Design, Development and Therapy

Purpose: Research comparing the clinical efficacy of dexlansoprazole and esomeprazole has been limited. This study aims to compare the clinical efficacy of single doses of dexlansoprazole (modified-release $60 \mathrm{mg}$ ) and esomeprazole $(40 \mathrm{mg}$ ) after 24-week followup in patients with mild erosive esophagitis.

Methods: We enrolled 86 adult GERD subjects, randomized in a 1:1 ratio to two sequence groups defining the order in which they received single doses of dexlansoprazole $(n=43)$ and esomeprazole $(n=43)$ for 8 weeks as initial treatment. Patients displaying complete symptom resolution (CSR) by the end of initial treatment ( 8 weeks) were switched to on-demand therapy until the end of 24 weeks. Follow-up endoscopy was performed either at the end of 24 weeks or when severe reflux symptoms occurred. Five patients were lost to follow-up, leaving 81 patients (dexlansoprazole, $n=41$; esomeprazole, $n=40$ ) in the per-protocol analysis.

Results: The GERDQ scores at 4-, 8-, 12-, 16-, 20-, and 24-week posttreatment were less than the baseline score. The CSR, rate of symptom relapse, days to symptom resolution, sustained healing rate of erosive esophagitis, treatment failure rate, and the number of tablets taken in 24 weeks were similar in both groups. The esomeprazole group had more days with reflux symptoms than the dexlansoprazole group ( $37.3 \pm 37.8$ vs $53.9 \pm 54.2 ; P=0.008)$. In the dexlansoprazole group, patients exhibited persistent improvement in the GERDQ score during the on-demand period (week 8 vs week $24 ; P<0.001$ ) but not in the esomeprazole group (week 8 vs week 24; $P=0.846$ ).

Conclusions: This study suggests that the symptom relief effect for GERD after 24 weeks was similar for dexlansoprazole and esomeprazole. Dexlansoprazole exhibited fewer days with reflux symptoms in the 24-week study period, with better persistent improvement in the GERDQ score in the on-demand period.

(ClinicalTrials. gov number: NCT03128736)

Keywords: dexlansoprazole, esomeprazole, 24-week response, gastroesophageal reflux disease, on-demand, GERDQ score

\section{Introduction}

Erosive esophagitis, caused by gastroesophageal reflux, is a common medical problem. At present, therapy for erosive esophagitis primarily focuses on the pharmacological reduction of gastric acid secretion. Decreasing the acidity of 
gastric juice ameliorates reflux symptoms and facilitates esophagitis healing. ${ }^{1,2}$ To date, several studies have indicated that the prospect of healing of esophagitis correlates directly with the potency of a medication's antisecretory effect. ${ }^{3-5}$ A comprehensive meta-analysis of 136 randomized controlled trials comprising 35,978 patients with esophagitis reported that the healing rate among patients treated with proton-pump inhibitors (PPIs; 83\%) was higher than that with histamine-2 receptor antagonists $(52 \%)$; of note, both rates were higher than that with placebo $(8 \%)^{3}{ }^{3}$

A large proportion of erosive esophagitis relapses, and only $10-25 \%$ of patients remain in remission after 6 months of stopping therapy. ${ }^{6,7}$ The relapse rate is driven, in part, by the underlying disease severity. Good evidence reveals that patients with severer esophagitis (Los Angeles [LA] grade C and D) are markedly more likely to relapse than those with mild esophagitis (ie, LA grade $\mathrm{A}$ and $\mathrm{B}){ }^{7}$ Considering the higher risk of relapse, most patients with documented severe esophagitis warrant long-term maintenance therapy. However, potential risks of long-term use of PPIs comprise secondary hypergastrinemia, malabsorption, and hypochlorhydria. ${ }^{8}$ In addition, population-based, epidemiological studies have reported that the long-term use of PPIs correlates with an elevated risk of hip fracture by a factor of 1.4 in patients aged $>50$ years, ${ }^{9}$ an increase in the risk of infectious gastroenteritis by a factor of $1.5,{ }^{10}$ and a doubling of the risk of Clostridium difficile colitis. ${ }^{11}$

A cost-effective analysis of the management strategies of erosive esophagitis established that initial therapy with PPIs followed by the on-demand therapy is the most costeffective approach. ${ }^{12,13}$ Nevertheless, the optimal duration of initial therapy remains unclear. Tytgat reported that the initial treatment of erosive esophagitis is the standard dose of PPI once a day for 3 months. ${ }^{14}$ Hsu et al reported that extending PPI therapy from 4 to 8 weeks reduced symptom relapse of GERD. ${ }^{15}$ Reportedly, both dexlansoprazole and esomeprazole are potent PPIs for gastric acid suppression with excellent symptom relief for patients with GERD. ${ }^{16-19}$ The benefit of dexlansoprazole MR (Takeda Pharmaceuticals, Osaka, Japan) is that it uses a novel approach through which its dual-delayed release (DDR) formulation extends the plasma concentration and, eventually, extends the acid suppression duration. ${ }^{16}$

To date, no study has directly investigated the 24-week clinical effects and timing to symptom relief of GERD between $60-\mathrm{mg}$ dexlansoprazole and 40-mg esomeprazole.
Hence, this open-label, randomized controlled trial aims to compare the 24-week clinical effects of single doses of dexlansoprazole $(60 \mathrm{mg})$ and esomeprazole $(40 \mathrm{mg})$ with initial 8-week treatment and shift to the on-demand use for patients with LA grades A and B erosive esophagitis.

\section{Materials and methods}

\section{Ethics statement}

This open-label, randomized controlled trial was conducted at Kaohsiung Chang Gung Memorial Hospital, Kaohsiung Medical University and the Hospital, and Kaohsiung Veterans General Hospital (Kaohsiung, Taiwan). This protocol was approved by the institutional review board and the Ethics Committee of Chang Gung Memorial Hospital (IRB-103-5384A3). We obtained written informed consent from all enrolled patients before participation. This clinical trial has been registered in a publicly accessible registry (ClinicalTrials. gov number: NCT03128736).

\section{Study population}

We invited patients aged 18-80 years with clinical symptoms of acid regurgitation, heartburn, or feeling of acidity in the stomach, who had LA grade A and B erosive esophagitis $^{20,21}$ proven by endoscopy for the assessment of eligibility $(\mathrm{n}=163)$. All patients underwent endoscopic procedures using the same video gastroscope (OLYMPUS EVIS LUCERA 260). In addition, narrow band imaging was used to assess the mucosal morphology at the squamocolumnar junction for enhancing the endoscopic diagnosis of GERD. ${ }^{22,23}$

We excluded 48 patients who declined to participate and 29 who fulfilled the following criteria: (1) taking antisecretory agents, such as PPIs and histamine- 2 receptor antagonists within 2 weeks before the endoscopy; (2) coexistence of a peptic ulcer or gastrointestinal malignancies; (3) pregnancy; (4) coexistence of serious concomitant illness (eg, decompensated liver cirrhosis and uremia); (5) previous gastric surgery; (6) allergy to esomeprazole; and (7) symptom score of a validated questionnaire (Chinese GERDQ) $<12$. All patients were requested to complete a Chinese GERDQ on recruitment, and the total score of GERD symptoms was recorded. ${ }^{20}$ In the scoring system, the selected symptoms comprised acid regurgitation, heartburn, and feeling of acidity in the stomach, which were graded on a 5-point Likert scale (supporting document). ${ }^{15,21,24,25}$ The Chinese GERDQ is a useful tool in diagnosing and managing GERD, with a cutoff score $\geq 12$ 
evaluated to discriminate between controls and GERD patients with a sensitivity of $82 \%$ and a specificity of $84 \%$. Furthermore, the GERDQ score has been used in the assessment of treatment response. ${ }^{20,43}$ For instance, in Wong et al, ${ }^{20}$ the Chinese GERDQ score exhibited significant improvement after 4-week PPI treatment than pretreatment (14.6 vs 19.7 ; $P<0.001)$ and score deterioration after the treatment withdrawal. We collected the following data from our participants: body mass index (BMI); serum fasting blood sugar; cholesterol; triglyceride levels; and endoscopic examination for Helicobacter pylori (H. pylori) using a rapid urease test by taking specimens from the $\leq 5 \mathrm{~cm}$ from the pylorus and from the greater curvature of the middle body.

\section{Study design}

Figure 1 shows the schematic flowchart of the study design. Using a computer-generated number sequence, all eligible patients with LA grade A and B erosive esophagitis were randomly assigned to each of two participant groups (dexlansoprazole $60 \mathrm{mg}$ q.d. or esomeprazole $40 \mathrm{mg}$ q.d. for 8 weeks as initial treatment). We requested all patients to complete a standard questionnaire for the complete medical history and demographic data. Next, patients returned to the clinics for drug refills, assessment of reflux symptoms, handed in daily symptom records and unused esomeprazole tablets at the end of treatment after $4,8,12,16,20$, and 24 weeks. Those who had complete symptom resolution (CSR) by the end of initial treatment ( 8 weeks) were switched to an on-demand therapy, using 40-mg esomeprazole daily or 60-mg dexlansoprazole for continuous 3 days if the GERD symptom relapse or until the end of 24 weeks. ${ }^{15}$ Follow-Up endoscopy was performed at the end of 24 weeks.

\section{Randomization}

Randomization was executed using a computer-generated list of random numbers. An independent staff member assigned the treatment based on consecutive numbers kept in sealed envelopes. Each patient completed diary $\operatorname{cards}^{14}$ during the study period.

\section{Endpoints}

In this study, the primary endpoint was the rate of sustained healing of erosive esophagitis (SHE) at the end of 24 weeks. The secondary outcome measures were as follows: (1) the CSR rate at the end of the initial treatment phase (the end of 8 weeks); (2) days to symptoms relieved; (3) the symptom relapse rate within 16 weeks after stopping the initial therapy; (4) failure rate of on-demand therapy after stopping the initial therapy, and switch to continuous PPI therapy; (5) the treatment failure rate in the 24-week therapy; (6) the number of days with reflux symptoms in 24 weeks; and (7) the number of tablets taken in 24 weeks. In addition, we observed sequential

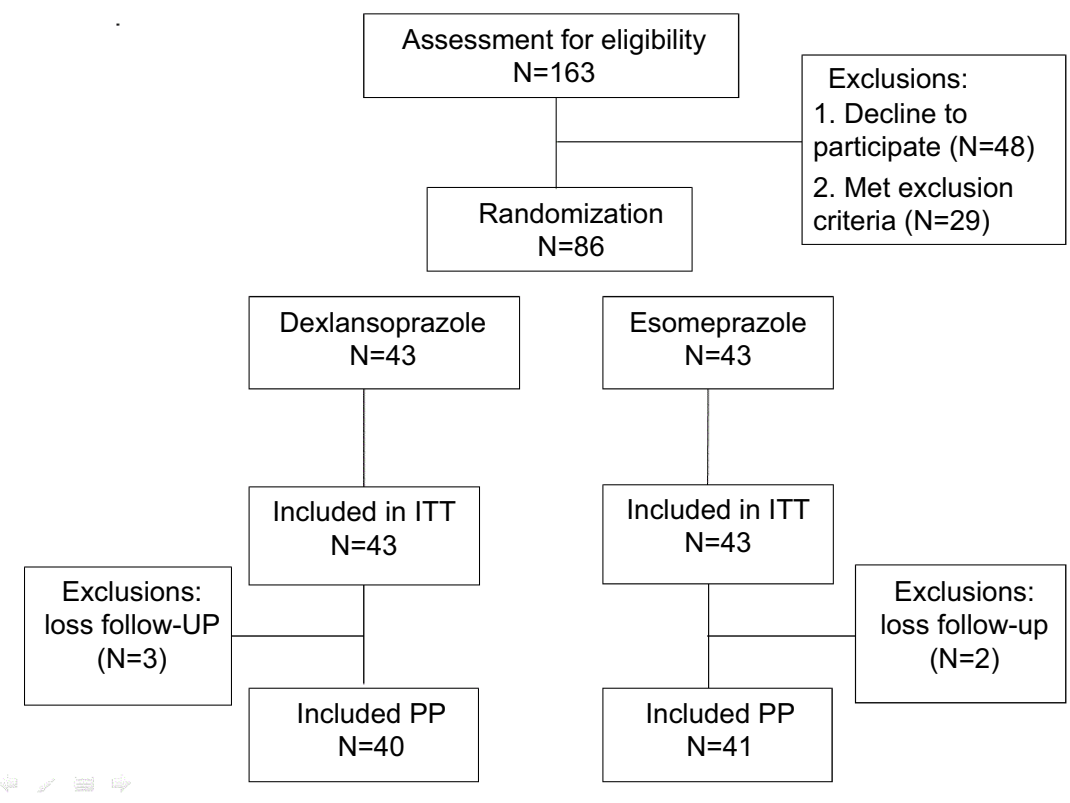

Figure I The schematic flowchart of the study design. Abbreviations: ITT, intent-to-treat; PP, per-protocol. 
changes in GERDQ scores during 24 weeks. All patients starting PPIs in initial treatment are included in the intentto-treat (ITT) analysis. If patients had poor drug compliance, they were excluded from the per-protocol (PP) analysis. We defined poor compliance as taking $<80 \%$ of the total medication in the initial treatment phase.

\section{Definition of outcomes}

We defined SHE as the absence of mucosal breaks over lower esophagus in the follow-up endoscopy. The CSR was defined for persons who specified no episodes of heartburn during the 7 days before the follow-up visit. ${ }^{26}$ Days to symptoms resolved was defined for the days from initial therapy to reflux symptom $<3$ points on the Likert scale. ${ }^{27}$ We defined symptom relapse as (1) $\geq 2$ episodes of troublesome reflux symptoms per week that impair the quality of life, or (2) ingestion of PPIs for $>7$ days for symptom relapse. ${ }^{21}$ In addition, switching to continuous therapy was defined for persons who could not stop taking PPIs for $>7$ days in the on-demand period. ${ }^{28}$ Furthermore, treatment failure was defined as (1) failure to attain the CSR in the initial treatment phase, (2) symptom relapse in the on-demand phase, or (3) the presence of mucosal breaks over lower esophagus in any follow-up endoscopy.

\section{Demographic data of patients}

We obtained a complete medical history and demographic data from each patient, including age, sex, medical history, history of smoking, alcohol, coffee and tea consumption, duration, frequency, and severity of reflux symptoms. Furthermore, compliance was checked by counting unused medication at the completion of treatment.

\section{Statistical analysis}

We evaluated the sample size was calculated as described previously. $^{29}$ The SHE after 24 weeks of mild erosive esophagitis (LA grades A and B) was assumed as $75 \%$. We estimated that the minimal requirement number were 102 patients in each treatment group to demonstrate a $10 \%$ absolute difference in the CSR with a type I error of 0.05 and a statistical power of $80 \%$ and assuming a $10 \%$ loss to follow-up. We used the chi-square test with or without Yates correction for continuity and Fisher's exact test when appropriate to compare the rates of CSR, symptom relapse, and esophagitis relapse between groups. In addition, the mean scores of reflux symptoms between groups were compared using the Wilcoxon's rank-sum test. All statistical analyses were performed using the SPSS program (version 10.1, Chicago, IL). We considered $P<0.05$ as statistically significant.

\section{Results}

Between January 2015 and March 2017, we enrolled 86 patients with endoscopy-confirmed LA grade A or B erosive esophagitis who started an 8-week course of PPIs for initial therapy for randomization after excluding 77 patients who declined to participate or fulfilled the exclusion criteria. Of these, 43 patients received the esomeprazole treatment, and 43 patients received dexlansoprazole treatment. As 5 patients were lost to follow-up, 81 patients were examined using the PP analysis (esomeprazole group, 41; dexlansoprazole group, 40; Figure 1). The baseline characteristics both groups were similar in age, sex, diet habits, BMI, and GERDQ score. The number of patients with LA grade B erosive esophagitis was higher in the dexlansoprazole group compared with the esomeprazole group, which was statistically significant (10 vs $3 ; P=0.030$; Table 1 ). The primary outcome of SHE for the dexlansoprazole and esomeprazole groups were $79.1 \%$ $(34 / 43, \quad 95 \% \quad \mathrm{CI}=64.0-90.0 \%) \quad$ vs $76.7 \% \quad(33 / 43,95 \%$ $\mathrm{CI}=61.3-88.2 \%, P=0.795)$ in the intention-to-treat analysis; and $85.0 \%(34 / 40,95 \% \mathrm{CI}=70.2-94.3 \%)$ vs $80.5 \%(33 / 41$, $95 \% \mathrm{CI}=65.2-91.2 \%, P=0.591)$ in the per-protocol analysis, which did not exhibit differences between the two groups. The secondary outcomes, such as CSR, symptom relapse rate, days to symptom resolved, treatment failure rate, and the number of tablets taken in 24 weeks, exhibited no statistical differences between the two groups. However, the esomeprazole group had more days with reflux symptoms in the study period than the dexlansoprazole group $(53.9 \pm 54.2$ vs $37.3 \pm 37.8$; $P=0.008$; Table 2).

In the serial follow-up for the GERDQ score posttreatment, the scores in the baseline, 4, 8, 12, 16, 20, and 24 weeks after treatment for the dexlansoprazole versus esomeprazole groups were $23.2 \pm 3.7$ vs $23.7 \pm 4.7$ $(P=0.878), 17.1 \pm 3.7$ vs $18.0 \pm 4.1 \quad(P=0.209), 16.4 \pm 3.6$ vs $16.9 \pm 3.7 \quad(P=0.686), \quad 16.3 \pm 4.0 \quad$ vs $17.4 \pm 4.7 \quad(P=0.124)$, $14.7 \pm 4.4$ vs $16.2 \pm 4.7 \quad(P=0.365), 13.7 \pm 3.2$ vs $15.0 \pm 4.8$ $(P=0.124)$, and $13.1 \pm 3.8$ vs $16.5 \pm 10.9(P=0.252)$, respectively (Table 3 ). The comparison of the serial GERDQ score change did not exhibit any difference between the two groups. In the dexlansoprazole group, patients displayed persistent improvement in the GERDQ score in the on-demand period (week 8 vs week 24; $P<0.001$ ), whereas no continuous improvement was noted in the esomeprazole group (week 8 vs week $24 ; P=0.846$ ) 
Table I The baseline characteristics of patients

\begin{tabular}{|c|c|c|c|}
\hline Variables & $\begin{array}{l}\text { Dexlansoprazole } \\
n=40(\%)\end{array}$ & $\begin{array}{l}\text { Esomeprazole } \\
n=4 I(\%)\end{array}$ & $P$-value \\
\hline Age $(y r)($ mean $\pm S D)$ & $46.9 \pm 12.5$ & $50.5 \pm 12.5$ & 0.899 \\
\hline Male sex - no. (\%) & $23(57.5)$ & $23(56.1)$ & 0.899 \\
\hline Smoking — no. (\%) & $9(22.5)$ & $5(\mid 2.2)$ & 0.220 \\
\hline Alcohol use — no. (\%) & $14(35.0)$ & $15(36.6)$ & 0.882 \\
\hline Ingestion of coffee - no. (\%) & $16(40.0)$ & $22(53.7)$ & 0.218 \\
\hline Ingestion of tea -no. (\%) & $29(72.5)$ & $29(70.7)$ & 0.860 \\
\hline Betel nut & $3(7.5)$ & $2(4.9)$ & 0.624 \\
\hline Spicy food & $28(70.0)$ & $27(65.9)$ & 0.689 \\
\hline Sweet food & $37(92.5)$ & $39(95.1)$ & 0.624 \\
\hline Body weight & $72.5 \pm 16.3$ & $67.3 \pm 13.1$ & 0.744 \\
\hline Body height & $163.2 \pm 17.3$ & $165.2 \pm 9.6$ & 0.449 \\
\hline BMI & $26.4 \pm 5.2$ & $24.5 \pm 3.6$ & 0.154 \\
\hline Waist girth & $90.6 \pm 10.9$ & $88.3 \pm 10.4$ & 0.960 \\
\hline Metabolic syndrome & $24(60.0)$ & $23(56.1)$ & 0.595 \\
\hline \multicolumn{4}{|l|}{ Hypertension } \\
\hline Systolic BP & $132.7 \pm \mid 4.4$ & $127.4 \pm 18.4$ & 0.093 \\
\hline Diastolic BP & $82.0 \pm 10.0$ & $79.8 \pm 9.6$ & 0.840 \\
\hline GERD history & $34(85.0)$ & $33(80.5)$ & 0.591 \\
\hline PPI dependence & $33(82.5)$ & $38(92.7)$ & 0.164 \\
\hline Anxiety & $24(60.0)$ & $\mid 7(4 \mid .5)$ & 0.095 \\
\hline Posture change during sleep & $23(57.5)$ & 16(39.0) & 0.177 \\
\hline Symptom score (GERDQ) & $23.2 \pm 3.7$ & $23.7 \pm 4.7$ & 0.878 \\
\hline Acid regurgitation score & $3.0 \pm 0.5$ & $3.3 \pm 0.6$ & 0.011 \\
\hline Heartburn score & $2.5 \pm 1.3$ & $2.6 \pm 1.2$ & 0.280 \\
\hline Epigastric acidity score & $2.9 \pm 0.8$ & $2.8 \pm 0.9$ & 0.778 \\
\hline \multicolumn{4}{|l|}{ Atypical symptoms } \\
\hline Chest pain & $25(62.5)$ & $24(58.5)$ & 0.715 \\
\hline Dysphagia & $13(32.5)$ & $15(36.6)$ & 0.699 \\
\hline Regurgitation of food & $14(35.0)$ & $22(53.7)$ & 0.111 \\
\hline Nausea & $15(37.5)$ & $\mid 7(4 \mid .5)$ & 0.715 \\
\hline Vomiting & $\mathrm{II}(27.5)$ & $15(36.6)$ & 0.318 \\
\hline Hiccup & $28(70.0)$ & $25(61.0)$ & 0.393 \\
\hline Foreign body sensation (throat) & $23(57.5)$ & $28(68.3)$ & 0.315 \\
\hline Foreign body sensation (chest) & $10(25.0)$ & $10(24.4)$ & 0.949 \\
\hline Hoarseness & $18(45.0)$ & 18(43.9) & 0.921 \\
\hline Throat cleaning & $21(52.5)$ & $24(58.5)$ & $0.48 I$ \\
\hline Cough & $17(42.5)$ & $22(53.7)$ & 0.314 \\
\hline Sore throat & $7(17.5)$ & $9(22.0)$ & 0.615 \\
\hline Dry mouth & $27(67.5)$ & $26(63.4)$ & 0.699 \\
\hline Bad breath & $14(35.0)$ & $15(36.6)$ & 0.882 \\
\hline Epigastric pain & $20(50.0)$ & $2 \mid(5 \mid .2)$ & 0.913 \\
\hline Epigastric fullness & $33(82.5)$ & $31(75.6)$ & 0.446 \\
\hline \multicolumn{4}{|l|}{ Insomnia } \\
\hline Early type & $18(45.0)$ & $15(36.6)$ & $0.44 I$ \\
\hline Meddle type & $10(25.0)$ & $12(29.3)$ & 0.666 \\
\hline Sinusitis & $6(15.0)$ & $9(22.0)$ & 0.421 \\
\hline Otitis media & $3(7.5)$ & $5(12.2)$ & 0.479 \\
\hline
\end{tabular}

(Continued) 
Table I (Continued).

\begin{tabular}{|l|l|l|l|}
\hline Variables & $\begin{array}{l}\text { Dexlansoprazole } \\
\mathbf{n = 4 0 ( \% )}\end{array}$ & $\begin{array}{l}\text { Esomeprazole } \\
\mathbf{n = 4} \text { (\%) }\end{array}$ & P-value \\
\hline Laboratory test & & & \\
Cholesterol & $198.7 \pm 37.8$ & $212.6 \pm 34.1$ & $103.1 \pm 53.5$ \\
TG & $129.5 \pm 57.2$ & $57.1 \pm 15.2$ & 0.627 \\
HDL & $53.5 \pm 19.6$ & $132.9 \pm 30.3$ & 0.925 \\
LDL & $121.6 \pm 33.5$ & & 0.856 \\
\hline H. pylolri infection & & $10(24.4)$ & 0.666 \\
Previous history - no. & $5(12.5)$ & $6(14.6)$ & 0.168 \\
Current infection - no. & $6(15.0)$ & & 0.852 \\
\hline Endoscopic findings & & $8(19.5)$ & \\
Hiatal hernia & $10(25.0)$ & $4(9.8)$ & 0.480 \\
GEFV (grade 3 or 4) & $5(12.5)$ & $3(7.3)$ & 0.027 \\
Esophagitis grade B & $10(25.0)$ & \\
\hline
\end{tabular}

Abbreviations: BMI, body mass index; BP, blood pressure; GERD, gastroesophageal reflux; PPI, proton pump inhibitor; GERDQ, gastroesophageal reflux questionnaire; TG, triglyceride; HDL, high-density lipoprotein ; LDL, low-density lipoprotein; GEFV, gastroesophageal flap valve.

Table 2 The outcomes of patients receiving dexlansoprazole or esomeprazole therapy with GERD A and B

\begin{tabular}{|c|c|c|c|}
\hline Variable & $\begin{array}{l}\text { Dexlansoprazole } \\
n=40(\%)\end{array}$ & $\begin{array}{l}\text { Esomeprazole } \\
n=41(\%)\end{array}$ & $P$-value \\
\hline \multicolumn{4}{|l|}{ SHE } \\
\hline ITT & $34(79.1)$ & $33(76.7)$ & .795 \\
\hline PP & $34(85.0)$ & $33(80.5)$ & .591 \\
\hline \multicolumn{4}{|l|}{ CSR } \\
\hline ITT & $21(48.8)$ & $21(48.8)$ & 1.000 \\
\hline PP & $21(52.5)$ & $21(5 \mid .2)$ & .908 \\
\hline \multicolumn{4}{|l|}{ Symptom relapse } \\
\hline ITT & $5(11.6)$ & $6(14.0)$ & .747 \\
\hline PP & $5(12.5)$ & $6(14.6)$ & .779 \\
\hline \multicolumn{4}{|l|}{ Switching to continuous therapy } \\
\hline ITT & $10(23.3)$ & 15(34.9) & .235 \\
\hline PP & $10(25.0)$ & $15(36.6)$ & .259 \\
\hline \multicolumn{4}{|l|}{ Treatment failure } \\
\hline ITT & $26(60.5)$ & $30(69.8)$ & .365 \\
\hline PP & $23(57.5)$ & $28(68.3)$ & .315 \\
\hline Days to symptom resolved & $9.2 \pm 14.4$ & $10.5 \pm 16.2$ & .700 \\
\hline Number of tables taken in the study period & $91.3 \pm 40.2$ & $96.7 \pm 44.9$ & .229 \\
\hline Number of days with reflux symptoms in the study period & $37.3 \pm 37.8$ & $53.9 \pm 54.2$ & .008 \\
\hline
\end{tabular}

Abbreviations: SHE, sustained healing of esophagitis; CSR, complete symptom resolution; PP, per-protocol analysis; ITT, intent-to-treat.

\section{Discussion}

Esomeprazole is a potent PPI with single release characteristics that produces the maximum plasma concentrations at approximately $1.6-\mathrm{h}$ post-dose. Daily administration of 40-mg esomeprazole yields good healing rates (87-94.1\%) in patients with erosive esophagitis after 8 weeks. ${ }^{18,19,30}$ A meta-analysis revealed that 40-mg esomeprazole exhibited statistically significant improvement in erosive esophagitis compared with other PPIs such as 20-mg omeprazole, 30-mg lansoprazole, and 40-mg pantoprazole. 
Table 3 Sequential changes of GERDQ scores during the 24-week study period

\begin{tabular}{|c|c|c|c|}
\hline Symptom score & $\begin{array}{l}\text { Dexlansoprazole } \\
(n=40)\end{array}$ & $\begin{array}{l}\text { Esomeprazole } \\
(n=4 I)\end{array}$ & $P$-value \\
\hline Week 0 & $23.2 \pm 3.7^{*}$ & $23.7 \pm 4.7^{i}$ & 0.878 \\
\hline Week 4 & $17.1 \pm 3.7$ & $18.0 \pm 4.1$ & 0.209 \\
\hline Week 8 & $16.4 \pm 3.6^{*, a}$ & $16.9 \pm 3.7^{\mathrm{int}}$ & 0.686 \\
\hline Week 12 & $16.3 \pm 4.0$ & $17.4 \pm 4.7$ & 0.124 \\
\hline Week 16 & $14.7 \pm 4.4$ & $16.2 \pm 4.7$ & 0.365 \\
\hline Week 20 & $13.7 \pm 3.2$ & $15.0 \pm 4.8$ & 0.124 \\
\hline Week 24 & $13.1 \pm 3.8^{\mathrm{a}}$ & $16.5 \pm 10.9$ & 0.252 \\
\hline
\end{tabular}

Notes: $* P<0.001,{ }^{i} P<0.001,{ }^{a} P<0.001,{ }^{t} P=0.846$

Abbreviation: GERDQ, Gastroesophgeal reflux disease questionnaire.

A study reported a $5 \%(\mathrm{RR}, 1.05 ; 95 \% \mathrm{CI}: 1.02-1.08)$ relative increase in the probability of healing of erosive esophagitis with esomeprazole, yielding an absolute risk reduction of $4 \%$ and the number needed to treat of $25 .^{31}$

Dexlansoprazole MR is the latest PPI that has been available in the United States for the treatment of acidrelated disorders since 2009. The DDR formulation of dexlansoprazole extends the plasma concentration and the duration of acid suppression. ${ }^{16,17}$ Metz et al revealed that a daily dose of $60-\mathrm{mg}$ dexlansoprazole MR controlled heartburn (median of $91-96 \%$ for $24-\mathrm{h}$ heartburn-free days, $96-99 \%$ for heartburn-free nights) satisfactorily. ${ }^{16}$ In a clinical trial, the 8-week healing of erosive esophagitis was $92-95 \%$ using dexlansoprazole MR. ${ }^{17}$ Comparative trials of dexlansoprazole compared with 30-mg lansoprazole illustrated superior control in esophageal $\mathrm{pH}$ values, and the convenience of being able to dose the drug any time of the day regardless of the food intake. ${ }^{32}$

To the best our best knowledge, no direct head-to-head comparative study has investigated the long-term clinical effects or serial symptom scores between $60-\mathrm{mg}$ dexlansoprazole and 40-mg esomeprazole. An indirect comparative study reported that $30-\mathrm{mg}$ dexlansoprazole was more effective than 20- or 40-mg esomeprazole (RR, 2.01; 95\% CI: $1.15-3.51$; RR, 2.17; 95\% CI: $1.39-3.38$ ) in the symptom control of heartburn in patients with nonerosive reflux disease (NERD) after 4 weeks. ${ }^{33}$ In Japan, the cumulative healing rate of $20-\mathrm{mg}$ esomeprazole during 24 weeks for GERD patients is $92.0 \%(88.0-96.0 \%) .{ }^{34}$ In a randomized, double-blind, placebo-controlled study, Johnson et al reported that the maintenance healing rate of erosive esophagitis was $93.6 \%$ after 24 weeks $(95 \%$ CI: 87.4-99.7) in patients treated with 40-mg esomeprazole. ${ }^{35}$ In addition, Howden et al reported that $60-\mathrm{mg}$ dexlansoprazole MR exhibited a significantly higher percentage of patients $(86.6 \%)$ who maintained healed erosive esophagitis over 24 weeks compared with placebo $(25.7 \%$; $P<0.00001)$ using the ITT population and life table analysis. ${ }^{36}$ Furthermore, Wu et al reported no significant differences between any doses of dexlansoprazole and esomeprazole in the maintenance of healed erosive esophagitis in the assessment of indirect comparisons. ${ }^{33}$

In this direct comparison study, the baseline acid regurgitation score was higher in the esomeprazole group than the dexlansoprazole group ( $3.3 \pm 0.6$ vs $3.0 \pm 0.5 ; P=0.011$ ). However, acid reflux sensation is one of the clinical symptoms of GERD, and heartburn score and epigastric acidity score were not statistically different between the two groups. In addition, the GERDQ score (contained 6 items) is a more objective questionnaire for the diagnosis and evaluation of the treatment efficacy ${ }^{20,43}$ of GERD than only one item. We observed no significant difference (23.2 \pm 3.7 vs $23.7 \pm 4.7 ; P=0.878)$ in the baseline GERDQ score of the two groups. Patients who completed the 8-week initial therapy were shifted to the on-demand treatment in the following study period. The overall CSR rates and the enhancement of the GERDQ score were similar between both groups. However, dexlansoprazole had lesser days with reflux symptoms in 24 weeks $(53.9 \pm 54.2$ vs 37.3 $\pm 37.8 ; P=0.008$ ). Moreover, we observed that patients exhibited persistent improvement in the GERDQ score in the on-demand period (week 8 vs week 24) in the dexlansoprazole group $(P<0.001)$, but no continuous improvement in the esomeprazole group (week 8 vs week $24 ; P=0.846$ ). Perhaps, different durations of drug retention exist in the circulation between two potent PPIs. According to a 1-week comparison study, 40-mg esomeprazole required more time (3 days) to attain CSR than $60 \mathrm{mg}$ dexlansoprazole, especially in the female group because of estrogen and progesterone enhancing the relaxants of lower esophageal 
sphincter. $^{37-39}$ In dexlansoprazole, no accumulation effect exists after multiple, once-daily doses of $60 \mathrm{mg}$, resulting in the maximum concentration $\left(C_{\max }\right)$ values of dexlansoprazole being slightly higher $(<10 \%)$ on day 5 than on day $1 .^{32,40}$ Consequently, dexlansoprazole could almost attain the target concentration on day 1. A one-day $\mathrm{pH}$ study comparing the pharmacokinetic effects of different PPIs after 12-24 $\mathrm{h}$ post-dose reported that the mean percentage of time with $\mathrm{pH}>4$ and the average of mean $\mathrm{pH}$ were higher for dexlansoprazole than esomeprazole (60\% vs $42 \%, P<0.001$ and 4.5 vs $3.5, \quad P<0.001$, respectively). ${ }^{41}$ However, this study did not report the clinical effect after tablets were used. Fass et al reported that $84 \%$ of patients who were previously on twice-daily esomeprazole were well controlled with once-daily dexlansoprazole for the maintenance of heartburn symptom relief. ${ }^{42}$ This study noted a trend that there were a fewer number of tables of dexlansoprazole than esomeprazole $(91.3 \pm 40.2$ vs $96.7 \pm 44.9)$ and less GERDQ score at 16, 20, and 24 weeks in the on-demand treatment for the dexlansoprazole than esomeprazole groups $(14.7 \pm 4.4$ vs $16.2 \pm 4.7$ $(P=0.365), 13.7 \pm 3.2$ vs $15.0 \pm 4.8(P=0.124)$, and $13.1 \pm 3.8$ vs $16.5 \pm 10.9(P=0.252)$, respectively), although they were not statistically significant. Perhaps, it is because of too small volume of study cases to meet the significant change. Hence, dexlansoprazole could be a more optimal once-daily dose PPI for the on-demand use than esomeprazole.

This study has several limitations. First, this study managed to enroll a small number of patients and, therefore, did not attain the target number. Nonetheless, this preliminary pilot study is the first study to compare the clinical efficacy of a 24-week treatment with 60-mg dexlansoprazole and 40-mg esomerazole for LA grade A and $B$ erosive esophagitis patients. Second, as the outcomes are subjective variables in this study, it could be essential to conduct a double-blind study to compare the treatment efficacy of two drugs.

\section{Conclusions}

In conclusion, this pilot study suggests that the symptom relief effect in 24 weeks for GERD was similar in dexlansoprazole and esomeprazole. Dexlansoprazole had lesser days with reflux symptoms in 24 weeks and better persistent improvement in the GERDQ score in the on-demand period. The dexlansoprazole could be a "more optimal" oncedaily dose PPI for patients needing the on-demand use. Furthermore, these findings could have crucial implications for clinical practice in the on-demand period when treating patients with mild erosive esophagitis. As this issue was hampered by the small sample size in this study, comprehensive comparative studies are warranted in the future.

\section{Ethics Approval and Informed Consent}

This prospective randomized trial was conducted in Kaohsiung Chang Gung Memorial Hospital (outpatient department) in Southern Taiwan. This protocol was approved by the institutional review board and the Ethics Committee of Chang Gung Memorial Hospital (IRB-103-5384A3). All patients provided their written informed consent before enrollment. None of our patients belonged to the minors'/children's group. The ClinicalTrials.gov registration identifier is NCT03128736. The study protocol conforms to the ethical guidelines of the 1975 Declaration of Helsinki as reflected in a priori approval by the institution's human research committee. There was no additional data available for data sharing statement.

\section{Acknowledgments}

The authors acknowledge Ms. Ching-Yi Lin for her assistance in this study and Enago, Crimson Interactive Inc. for his assistance in English revisions. This study was supported by the Research Foundation of Chang Gung Memorial Hospital (No. CMRPG8D1441).

\section{Author contributions}

All authors contributed toward data analysis, drafting, and revising the article, gave final approval of the version to be published, and agree to be accountable for all aspects of the work.

\section{Disclosure}

The authors report no conflicts of interest in this work.

\section{References}

1. Kahrilas PJ. Gastroesophageal relfux disease. $N$ Engl J Med. 2008;359 (16):1700-1707. doi:10.1056/NEJMcp0804684

2. Moayyedi P, Talley N. Gastro-esophageal reflux disease. Lancet. 2006;367(9528):2086-2100. doi:10.1016/S0140-6736(06)68932-0

3. Khan M, Santana J, Donnellan C. Medical treatment in the short term management of reflux esophagitis. Cochrane Database Syst Rev. 2007;2:CD003244.

4. Chiba N, De Gara CJ, Wilkinson JM, et al. Speed of healing and symptom relief in grade II to IV gastroesophageal reflux disease: a meta-analysis. Gastroenterology. 1997;112(6):1798-1810.

5. Kahrilas PJ, Fennerty MB, Joelsson B. High- versus standard-dose ranitidine for control of heartburn in poorly response gastroesophgeal reflux disease: a prosptive, controlled trial. Am J Gastroenterol. 1999;94(1):92-97. doi:10.1111/j.1572-0241.1999.00777.x 
6. Donnellan C, Sharma N, Preston C. Medical treatments for the maintenance therapy of reflux oesophagitis and endoscopic negative reflux disease. Cochrane Database Syst Rev. 2005;2:CD003245.

7. Dent J, Talley NJ. Overview: initial and long-term management of gastro-oesophageal reflux disease. Aliment Pharmacol Ther. 2003;17 (Suppl 1):53-57. Review.

8. Laine L, Ahnen D, McClain C, et al. Review article: potential gastrointestinal effects of long-term acid suppression with proton pump inhibitors. Aliment Pharmacol Ther. 2000;14(6):651-668. Review.

9. Yang YX, Lewis JD, Epstein S, et al. Long-term proton pump inhibitor therapy and risk of hip fracture. JAMA. 2006;296 (24):2947-2953. doi:10.1001/jama.296.24.2947

10. Garcia Rodríguez LA, Ruigómez A. Gastric acid, acid-suppressing drugs, and bacterial gastroenteritis: how much of a risk? Epidemiology. 1997;8(5):571-574.

11. Dial S, Alrasadi K, Manonkian C, et al. Risk of Clostridium difficile among hospital inpatients prescribed proton pump inhibitors: cohor and case-control studies. Cmaj. 2004;171(1):33-38.

12. Gerson LB, Robbins AS, Garber A, et al. A cost-effectiveness analysis of prescribing strategies in the management of gastroesophageal reflux disease. Am J Gastroenterol. 2000;95(2):395-407. doi:10.1111/j.15720241.2000.01759.x

13. Vakil N. Review article: cost-effectiveness of different GERD management strategies. Aliment Pharmacol Ther. 2002;16(Suppl 4):79-82. Review.

14. Tytgat GN. Review article: management of mild and severe gastro-oesophageal reflux disease. Aliment Pharmacol Ther. 2003;17(Suppl 2):52-56. Review.

15. Hsu PI, Lu CL, Wu DC, et al. Eight weeks of esomeprazole therapy reduces symptom relapse, compared with 4 weeks, in patients with Los Angeles grade A or B erosive esophagitis. Clin Gastroenterol Hepatol. 2015;13(5):859-866. doi:10.1016/j. cgh.2014.09.033

16. Metz DC, Howden CW, Perez MC, et al. Clinical trial: dexlansoprazole MR, a proton pump inhibitor with dual delayed-release technology, effectively controls symptoms and prevents relapse in patients with healed erosive oesophagitis. Aliment Pharmacol Ther. 2009;29 (7):742-754. doi:10.1111/j.1365-2036.2009.03954.x

17. Sharma P, Shaheen NJ, Perez MC, et al. Clinical trials: healing of erosive oesophagitis with dexlansoprazole MR, a proton pump inhibitor with a novel dual delayed-release formulation-results from two randomized controlled studies. Aliment Pharmacol Ther. 2009;29 (7):731-741. doi:10.1111/j.1365-2036.2009.03933.x

18. Richter JE, Kahrilas PJ, Johanson J, et al; Esomeprazole Study Investigators. Efficacy and safety of esomeprazole compared with omeprazole in GERD patients with erosive esophagitis: a randomized controlled trial. Am J Gastroenterol. 2001;96 (3):656-665. doi:10.1111/j.1572-0241.2001.3600 b.x

19. Schmitt C, Lightdale CJ, Hwang C, et al. A multicenter, randomized, double-blind, 8-week comparative trial of standard doses of esomeprazole $(40 \mathrm{mg})$ and omeprazole $(20 \mathrm{mg})$ for the treatment of erosive esophagitis. Dig Dis Sci. 2006;51(5):844-850. doi:10.1007/s10620005-9062-4

20. Wong WM, Lai KC, Lam KF, et al. Prevalence, clinical spectrum and health care utilization of gastro-oesophageal reflux disease in a Chinese population: a population-based study. Aliment Pharmacol Ther. 2003;18(6):595-604.

21. Lundell LR, Dent J, Bennett JR, et al. Endoscopic assessment of oesophagitis: clinical and functional correlates and further validation of the Los Angeles classification. Gut. 1999;45 (2): $172-180$.

22. Fock KM, Teo EK, Ang TL, et al. The utility of narrow band imaging in improving the endoscopic diagnosis of gastroesophageal reflux disease. Clin Gastroenterol Hepatol. 2009;7(1):54-59. doi:10.1016/ j.cgh.2008.08.030
23. Kasap E, Zeybel M, Aşık G, et al. Correlation among standard endoscopy, narrow band imaging, and histopathological findings in the diagnosis of nonerosive reflux disease. $J$ Gastrointestin Liver Dis. 2011;20(2):127-130.

24. Vakil N, van Zanten SV, Kahrilas P, et al; Global Consensus Group. The Montreal definition and classification of gastroesophageal reflux disease: a global evidence-based consensus. Am J Gastroenterol. 2006;101(8):1900-1920. doi:10.1111/j.1572-0241.2006.00630.x

25. Hu WHC, Lam KF, Wong YH, et al. The Hong Kong index of dyspepsia: a validated symptom severity questionnaire for patients with dyspepsia. J Gastroenterol Hepatol. 2002;17(5):545-551.

26. Revicki DA, Crawley JA, Zodet MW, et al. Complete resolution of heartburn symptoms and health-related quality of life in patients with gastro-oesophageal reflux disease. Aliment Pharmacol Ther. 1999;13 (12):1621-1630.

27. Remes-Troche JM, Sobrino-Cossio S, Soto-Perez JC, et al. Efficacy, safety, and tolerability of pantoprazole magnesium in the treatment of reflux symptoms in patients with gastroesophageal reflux disease (GERD): a prospective, multicenter, post-marketing observational study. Clin Drug Investig. 2014;34(2):83-93. doi:10.1007/s40261-013-0135-4

28. Tytgat G. Long-term GERD management: the individualized approach. Drugs Today (Barc). 2006;42(Suppl B):23-29. Review.

29. Revicki DA, Zodet MW, Joshua-Gotlib S, et al. Health-related quality of life improves with treatment-related GERD symptom resolution after adjusting for baseline severity. Health Qual Life Outcomes. 2003;29(1):73. doi:10.1186/1477-7525-1-73

30. Kahrilas PJ, Falk GW, Johnson DA, et al; The Esomeprazole Study Investigators. Esomeprazole improves healing and symptom resolution as compared with omeprazole in reflux oesophagitis patients: a randomized controlled trial. Aliment Pharmacol Ther. 2000;14 (10):1249-1258.

31. Gralnek IM, Dulai GS, Fennerty MB, et al. Esomeprazole versus other proton pump inhibitors in erosive esophagitis: a meta-analysis of randomized clinical trials. Clin Gastroenterol Hepatol. 2006;4 (12):1452-1458. doi:10.1016/j.cgh.2006.09.013

32. Metz DC, Vakily M, Dixit T, et al. Review article: dual delayed release formulation of dexlansoprazole MR, a novel approach to overcome the limitations of conventional single release proton pump inhibitor therapy. Aliment Pharmacol Ther. 2009;29 (9):928-937. doi:10.1111/j.1365-2036.2009.03984.x

33. Wu MS, Tan SC, Xiong T. Indirect comparison of randomised controlled trials: comparative efficacy of dexlansoprazole vs. esomeprazole in the treatment of gastro-oesophageal reflux disease. Aliment Pharmacol Ther. 2013;38(2):190-201. doi:10.1111/apt.12349

34. Sugimoto M, Furuta T. Efficacy of esomeprazole in treating acid-related diseases in Japanese populations. Clin Exp Gastroenterol. 2012;5:49-59. doi:10.2147/CEG.S23926

35. Johnson DA, Benjamin SB, Vakil NB, et al. Esomeprazole once daily for 6 months is effective therapy for maintaining healed erosive esophagitis and for controlling gastroesophageal reflux disease symptoms: a randomized, double-blind, placebo-controlled study of efficacy and safety. Am J Gastroenterol. 2001;96(1):27-34. doi:10.1111/ j.1572-0241.2001.03443.x

36. Howden CW, Larsen LM, Perez MC, et al. Clinical trial: efficacy and safety of dexlansoprazole MR 60 and $90 \mathrm{mg}$ in healed erosive oesophagitis - maintenance of healing and symptom relief. Aliment Pharmacol Ther. 2009;30(9):895-907. doi:10.1111/j.1365-2036.2009.04119.x

37. Liang CM, Kuo MT, Hsu PI, et al. First-week clinical responses to dexlansoprazole $60 \mathrm{mg}$ and esomeprazole $40 \mathrm{mg}$ for the treatment of grades A and B gastroesophageal reflux disease. World J Gastroenterol. 2017;23(47):8395-8404. doi:10.3748/wjg. v23.i47.8395

38. Smout AJPM; Gastro-oesophageal reflux disease. Pathogenesis and diagnosis. In: Champion MC, Orr WC editors. Evolving Concepts in Gastrointestinal Motility. Oxford, England: Blackwell Science; 199646-63. 
39. Van Thiel DH, Gavaler JS, Stremple J. Lower esophageal sphincter pressure in women using sequential oral contraceptives. Gastroenterology. 1976;71(2):232-234.

40. Behm BW, Peura DA. Dexlansoprazole MR for the management of gastroesophageal reflux disease. Expert Rev Gastroenterol Hepatol. 2011;5(4):439-445. doi:10.1586/egh.11.37

41. Kukulka M, Eisenberg C, Nudurupati S. Comparator $\mathrm{pH}$ study to evaluate the single-dose pharmacodynamics of dual delayed-release dexlansoprazole $60 \mathrm{mg}$ and delayed-release esomeprazole $40 \mathrm{mg}$. Clin Exp Gastroenterol. 2011;4:213-220. doi:10.2147/CEG.S24063
42. Fass R, Inadomi J, Han C, et al. Maintenance of heartburn relief after step-down from twice-daily proton pump inhibitor to once-daily dexlansoprazole modified release. Clin Gastroenterol Hepatol. 2012;10(3):247-253. doi:10.1016/j.cgh.2011.11.021

43. Suzuki H, Matsuzaki J, Okada S, et al. Validation of the GerdQ questionnaire for the management of gastro-oesophageal reflux disease in Japan. United European Gastroenterol J. 2013;1 (3):175-183. doi:10.1177/2050640613485238

\section{Publish your work in this journal}

Drug Design, Development and Therapy is an international, peerreviewed open-access journal that spans the spectrum of drug design and development through to clinical applications. Clinical outcomes, patient safety, and programs for the development and effective, safe, and sustained use of medicines are a feature of the journal, which has also been accepted for indexing on PubMed Central. The manuscript management system is completely online and includes a very quick and fair peer-review system, which is all easy to use. Visit http://www. dovepress.com/testimonials.php to read real quotes from published authors. 